\title{
Light and Electron Microscopy of Bone Marrow Hemo- poiesis in Late Embryonal and Early Postnatal Mice: A Qualitative and Quantitative Study*
}

\author{
Kazunobu Sasaki, George Matsumura and Takashi ITo \\ Department of Anatomy (Prof. T. Iто), Hokkaido University School of Medicine, Sapporo, Japan
}

Received August 15, 1983

\begin{abstract}
Summary. Using serial sections of the entire body of late embryonal and early postnatal mice, a morphologic analysis of the bone marrow in the whole skeleton was made qualitatively and quantitatively. Hemopoietic cells in the developing marrow were also examined at the light and electron microscopic levels.

Before birth, the bone marrow is quite small in volume. During the first five postnatal days, the marrow shows an approximately 65-fold increase in total volume. At 0-3 days of age, hemopoiesis begins in the marrow throughout the body. Marrow hemopoiesis starts earlier in the rib, scapula, humerus and femur.

The development of hemopoiesis proceeds through the following three stages: 1) formation of the marrow cavity, 2) accumulation of neutrophils in the cavity, and 3) appearance of hemopoietic cells. In the bone marrow prior to active hemopoiesis, a majority of cells first appearing are mature neutrophils, among which immature ery throblasts and dark small lymphocytes, although very small in number, are seen. The functional significance of the cells appearing early is discussed in relation to the sequent events involved in marrow hemopoiesis. In addition to the marrow, development of the other blood forming tissues and lymphatic organs is also examined quantitative-morphologically.
\end{abstract}

Accurate quantitative estimation of a total volume of the bone marrow is difficult to obtain, because the bone marrow is widely distributed throughout the body. Measurement of the marrow volume has been made for various animal species including human being (Mechanik, 1926; Dietz, 1931; Nye, 1931; Fairman and Corner, 1934; Kindred, 1942; Hudson, 1958). In a majority of the quantitative studies, the marrow volume has been estimated indirectly, for example, using macerated bones. On the other hand, regarding developing hemopoiesis in the bone marrow, many morphological studies have been published (Kalpaktsoglou and Emery, 1965; Bukulya and Balázs, 1968; EARL et al., 1973; CHEN and WeIss, 1975; HAAs et al., 1976), but little systematic information is available about the sequent events involved in the developing marrow throughout the entire body.

In this study, using serial sections of the mouse in toto, the bone marrow in the whole body in late embryonal to early postnatal life was morphologically investigated quantitatively and qualitatively to fulfil gaps in our knowledge on the development of

*This work was supported by a grant from Japanese Ministry of Education 1982, 1983 (No. 57480089). 
marrow hemopoiesis. In addition to the marrow, development of the other blood forming and lymphatic organs was also examined.

\section{MATERIALS AND METHODS}

A total of sixteen dd-mice were used in this study: 18-day-fetal, 0-day-, 3-day- and 5-day-old mice. Adult females were randomly mated with males, and the morning following mating was designated at the zero time of gestation. The mice were killed with chloroform after weighing.

\section{Light microscopy}

The mice were placed in toto in a mixture of $10 \%$ formalin and $10 \%$ formic acid for $24 \mathrm{hrs}$. Then they were cut into halves by razor blades on median sagittal plane and further remained in the fixing solution. After fixation and decalcification for four days in several changes of the solution, the mice were dehydrated in graded ethanols, and embedded in paraffin. Sagittal sections were cut serially at $10 \mu \mathrm{m}$ and then stained with hematoxylin and eosin (Fig. 1).

Volumetry: The volume of the bone marrow in the whole skeleton was obtained in the following way. For every bone, the marrow contained was examined at $200 \times$ magnification, and using a grid in the eyepiece, the number of intersections lying within the marrow filled with the hemopoietic tissue was counted. The point-counting was carried out at every interval of $100 \mu \mathrm{m}$ in serial sections. Then, for each mouse, the volume of the bone marrow was estimated from both the number of points and a unit volume which one point represented

The volume of the spleen, thymus, lymph nodes and Peyer's patches was also obtained in the same way as for the bone marrow. For the spleen, the number of points lying on the red and white pulp was counted separately.

\section{Electron microscopy}

In 3-day-old and 5-day-old mice the mandible was quickly removed and cut into pieces so that the marrow was exposed to the fixative. Then

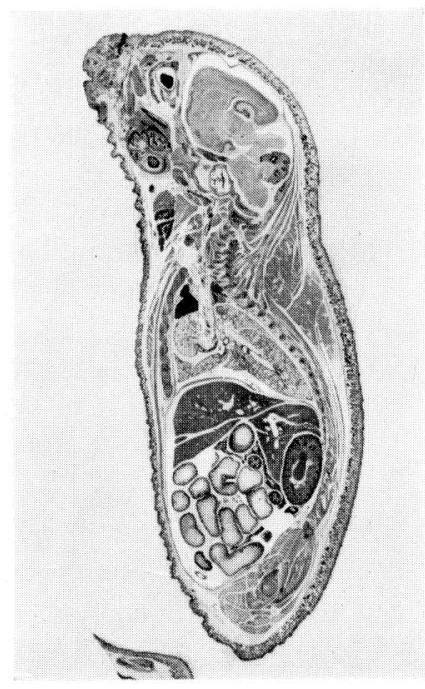
the tissue pieces were immediately fixed in an ice-cold mixture containing $5 \%$ formalin and $1 \%$ glutaraldehyde in $0.1 \mathrm{M}$ cacodylate buffer, $\mathrm{pH} 7.5$, for 2 hrs. After postfixation in $2 \% \mathrm{OsO}_{4}$ for $2 \mathrm{hrs}$, the tissues were decalcified in $1 \%$ ascorbic acid for 24 hrs (Dietrich and Fontaine, 1975). Then the tissues were immersed in $0.5 \%$ uranyl acetate overnight, dehydrated in graded ethanols and embedded in Quetol 812. Ultrathin sections were cut, stained with lead citrate and examined by electron microscopy.

Fig. 1. A sagittal section of a 5-day-old mouse. Hematoxylineosin. $\times 2.2$ 


\section{RESULTS}

\section{A. Quantitative studies}

\section{Volume of the bone marrow}

The total volume of the hemopoietic bone marrow in late embryonal and early postnatal life is shown in Figure 2. Evaluation of the total amount of marrow in the skeleton gives $0.3 \times 10^{8} \mu \mathrm{m}^{3}$ in the 18 -day-embryo, $1.5 \times 10^{8} \mu \mathrm{m}^{3}$ in the neonate, and 98.6 $\times 10^{8} \mu \mathrm{m}^{3}$ in the 5 -day-old mouse. Thus, the bone marrow shows an approximately 65 -fold increase in volume during the first five days after birth.

For various parts of the bony skeleton, the volume rates $(\%)$ of the marrow at various ages are shown in Figure 3. In the 18-day-embryo and the neonate, the volume of marrow in the upper and lower limbs accounts for up to $50 \%$ of the total marrow volume. The bone marrow in the vertebral column is $3 \%$ of the total bone marrow in the 18 -day-embryo and $30 \%$ in the 5 -day-old mouse. Thus the vertebral marrow shows a marked increase in volume during the short period after birth.

Fig. 2. Total volume of the bone marrow, thymus, spleen and lymph nodes at the 18 th day of embryonic life (18d-E), at birth (Od) and at 5 days after birth (5d). $B M$ bone marrow, $T m$ thymus, $S p$ spleen, $L N$ lymph nodes.
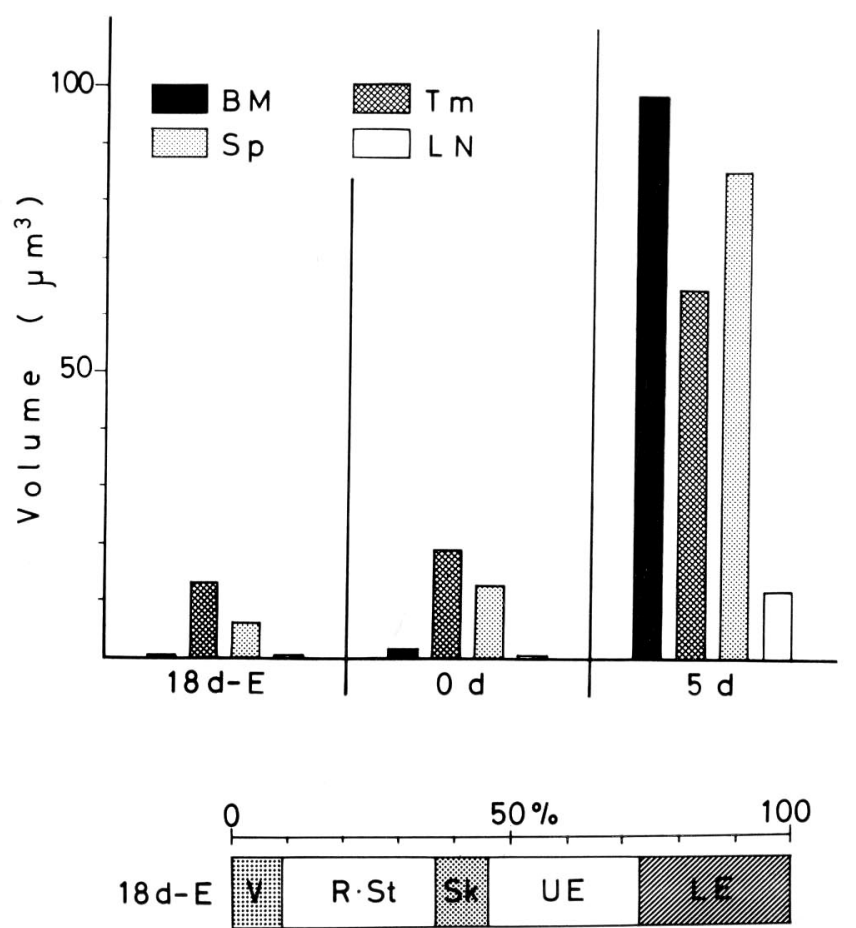

Fig. 3. Volume rate of the marrow in various parts of the skeleton. $V$ vertebrae, $R \cdot S t$ ribs and sternum, $S k$ skull, $U E$ upper extremities, $L E$ lower extremities. The other abbreviations are the same as in Figure 2.

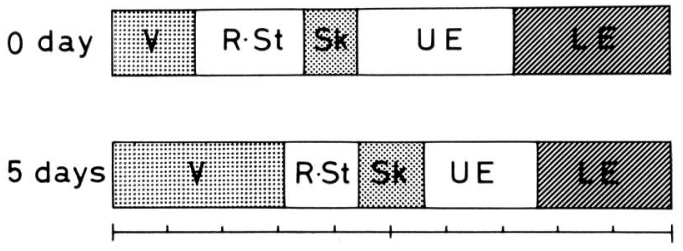


The volume of hemopoietic tissue in the bone marrow in various components of the skeleton at 5 days of age is presented in Figure 4 . The volume $\left(\mu \mathrm{m}^{3}\right)$ of marrow is $30.5 \times 10^{8}$ in the vertebrae; $10.6 \times 10^{8}$ in the ribs; $2.5 \times 10^{8}$ in the sternum; $11.2 \times 10^{8}$ in the skull; $20.1 \times 10^{8}$ in the upper extremities (the scapulae and clavicles $6.7 \times 10^{8}$, the humeruses $7.5 \times 10^{8}$, the radiuses and ulnas $3.9 \times 10^{8}$, the bones of the hands $\left.2.0 \times 10^{8}\right)$; $23.7 \times 10^{8}$ in the lower extremities (the hip bones $6.8 \times 10^{8}$, the femora $7.7 \times 10^{8}$, the tibias and fibulas $7.5 \times 10^{8}$, the bones of the feet $\left.1.7 \times 10^{8}\right)$. Thus, out of all the bones, the humerus and femur have the largest hemopoietic marrow, about $7.7 \%$ of the total marrow, respectively, at 5 days of age.

\section{Volume of the spleen}

The spleen considerably increases in volume from the 18th day of embryonic life to 5 th day after birth (Fig. 2). The mouse spleen is composed of two pulps, red and white. In the embryo, however, the white pulp is quite negligible in volume, and most of the splenic pulp is red one. Even at 5 days of age, the red pulp accounts for $85.5 \%$ of the splenic pulp in volume. Therefore, the volumetric increase of the spleen in early life is mainly due to that of the red pulp. The red pulp is two times larger in volume at birth than at 18 days of embryo. It is increased 14 -fold at 5 days over that of the embryo. The white pulp has only one-sixth of the thymus in volume at 5 days of age.

\section{Volume of the lymphatic tissue}

The total volume of the thymus and lymph nodes is shown in Figure 2. At the 18th

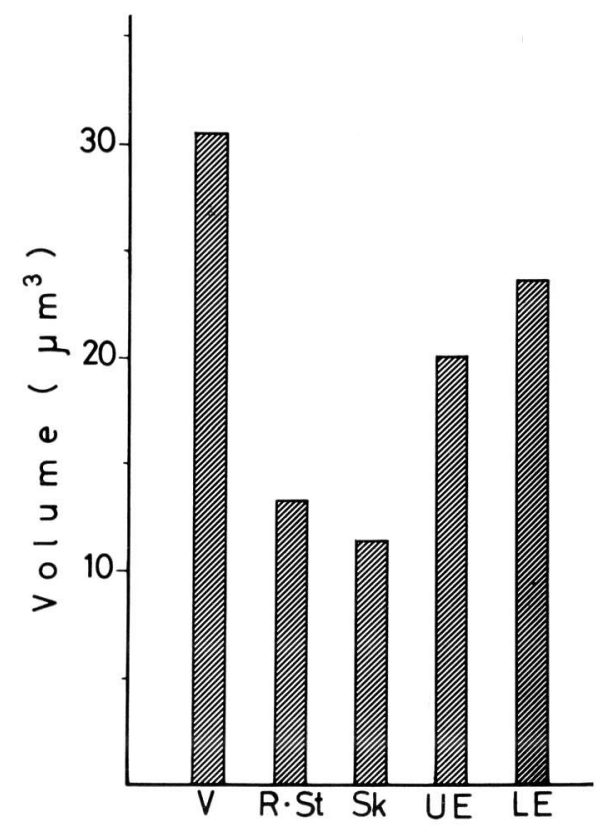

Fig. 4. Volume of the hemopoietic marrow in various components of the skeleton at 5 days of age. $V$ vertebrae, $R \cdot S t$ ribs and sternum, $S k$ skull, $U E$ upper extremities, $L E$ lower extremities.

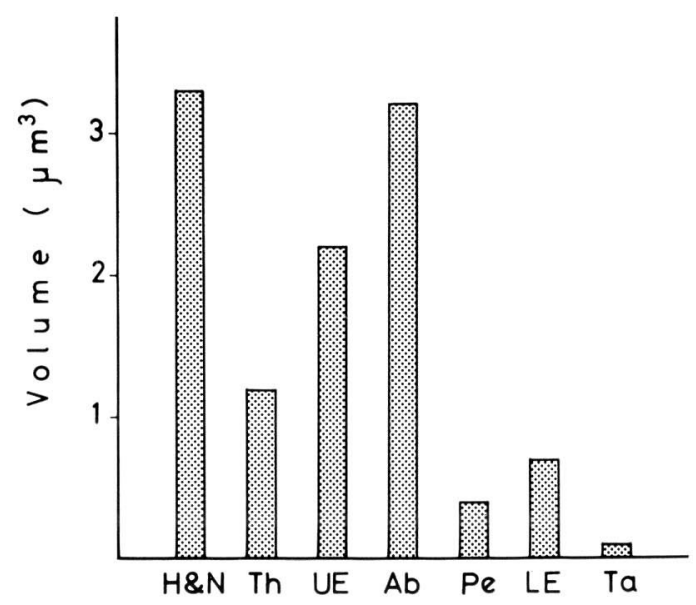

Fig. 5. Volume of lymph nodes in various regions at 5 days of age. $H$ and $N$ head and neck, Th thorax, UE upper extremities, $A b$ abdomen, $P e$ pelvis, $L E$ lower extremities, $T a$ tail. 
day of embryonic life, the thymus is the largest of the lymphatic tissues in volume, $13.1 \times 10^{8} \mu \mathrm{m}^{3}$. The thymus shows a further marked increase in volume during the first five days of age.

On the other hand, lymph nodes are quite negligible in volume before birth. In a very short time after birth, however, they rapidly develop and show about a 60 -fold increase in volume during five days after birth. At birth, lymph nodes are found only in small numbers in the neck and around the root of the mesentery. They are observed in various regions of the body at 5 days of age. According to Tilney (1971), lymph nodes are regionally divided into seven groups, such as shown in Figure 5 . The volume of the regional lymph nodes at 5 days is presented in this figure. Nodes in the head and neck and the abdomen are the largest in volume at 5 days of age.

Peyer's patches first appear at 3 days, and their volume is only one-tenth of the total volume of the lymphatic tissue at 5 days of age.

\section{B. Development of hemopoiesis in the bone marrow}

\section{Light microscopy}

During late embryonic and early postnatal life, hemopoiesis in the bone marrow exhibits remarkable development.

18-day-embryo: The marrow space, although quite narrow, is formed mainly in the axial skeleton and long bones. Small accumulations of blood cells are seen in the marrow cavity of the vertebra, rib, scapula, humerus and femur. A majority of the blood cells are neutrophils with characteristically lobulated or ring-shaped nuclei. In the other bones, the marrow has expanded sinusoids, around which quite few blood cells are seen.

O-day after birth: The marrow cavity appears not only in the axial and appendicular skeletons but also in the skull. In the cavity, the vast majority of marrow cells are neutrophils, which accumulate around the blood vessels.

3-day after birth: Except for the skull and the bones of the hand and foot, the bone marrow contains a number of erythroblasts and megakaryocytes in addition to neutrophils. The marrow cavity of the skull bone is almost occupied by neutrophils.

5-day after birth: Erythroblasts and megakaryocytes are increased in number in the marrow of various bones. In the tarsal and metatarsal bones, the marrow cavity is usually filled with only neutrophils.

In Figure 6, the above-mentioned development of the hemopoietic marrow is shown in the lumbar vertebra. It is likely that development of hemopoiesis in the bone marrow proceeds successively through the following three stages: 1) formation of the marrow space, 2) accumulation of neutrophils around the vessels in the marrow cavity, and 3) appearance of hemopoietic cells in the cavity.

The three stages in development of hemopoiesis in the marrow of various bones are shown in Figure 7. As shown in this figure, the marrow hemopoiesis starts earlier in the rib, scapula, humerus and femur, and later in the distal bones of the upper and lower extremities.

\section{Electron microscopy}

As shown in Figure 7, the marrow cavity of the mandible is formed in the 18-dayembryo. At 0 and 3 days of age, the marrow is characterized by the accumulation of neutrophils, stage II. The marrow is actively hemopoietic, stage III, at 5 days of age.

In the marrow cavity of the mandible at 3 days of age, neutrophils, a majority of blood cells, are collected in groups around and between the sinusoids (Fig. 8). The 
neutrophils, round or ovoid in outline, have a lobulated or C-shaped nucleus, and contain numerous granules (Fig. 9, 10). Erythroblasts and lymphocytes, although few in number, are found among neutrophils.

Erythroblasts, ranging between 6 and $9 \mu \mathrm{m}$ in cellular diameter, have round or ovoid, light nuclei which, measuring $5.5-6.0 \mu \mathrm{m}$ in diameter, have large prominent nu-

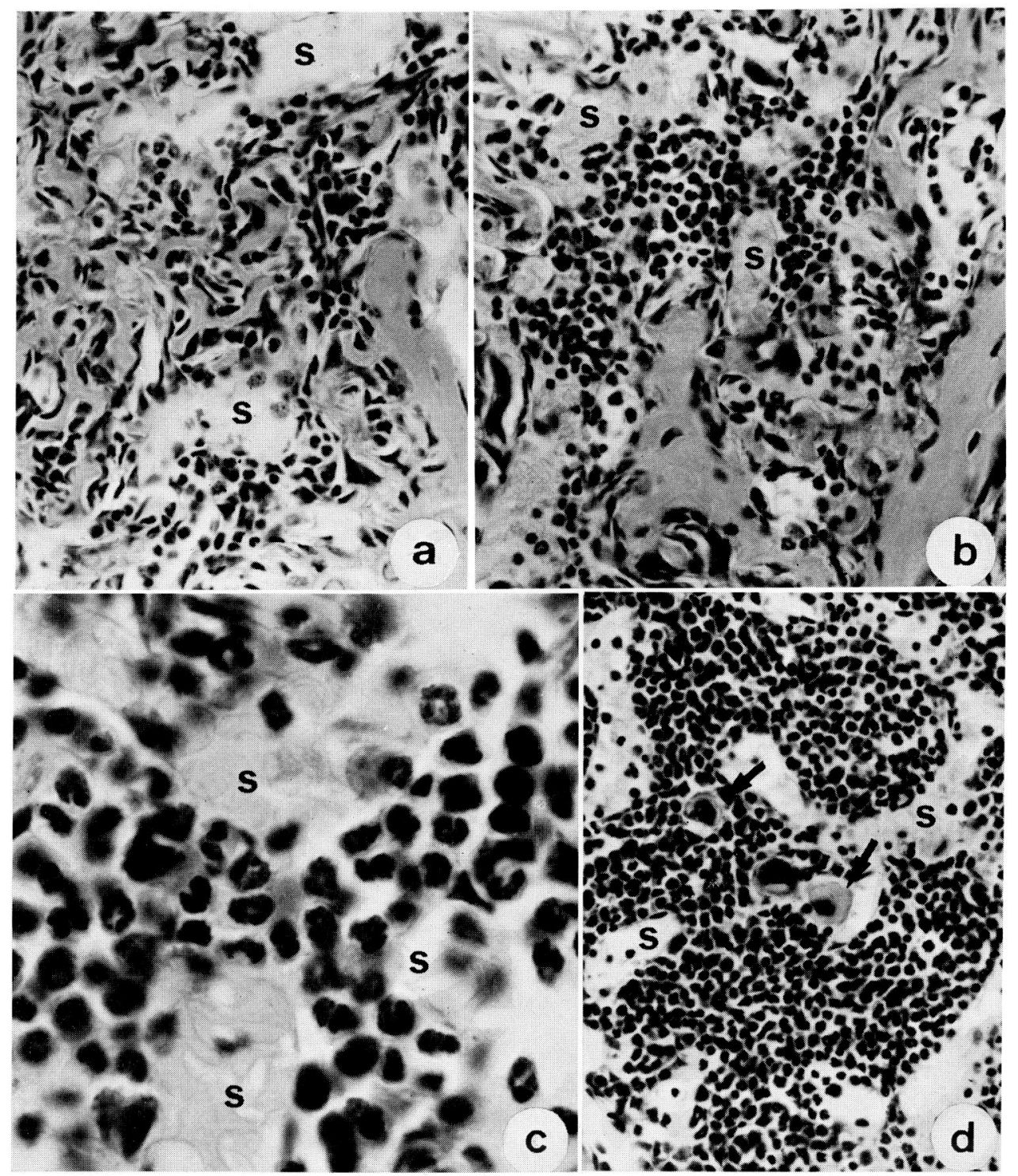

Fig. 6. Light micrographs of bone marrow in the lumbar vertebra at various ages. a. 18-day embryo. In the narrow marrow, sinusoids $(s)$ are expanded. There are almost no or few blood cells. H-E, $\times 340$. b. Newborn mouse. Accumulations of blood cells are seen around the sinusoids (s). H-E, $\times 340$. c. Newborn mouse. Accumulation of blood cells around the sinusoids $(s)$ is formed of neutrophils. H-E, $\times 1,100$. d. 5 -day-old mouse. Various series of hemopoietic cells are seen in the marrow cavity. Arrows indicate megakaryocytes, $s$ sinusoid. $\mathrm{H}-\mathrm{E}, \times 170$ 
cleoli and minute peripheral clumps of chromatin (Fig. 9). Erythroblasts sometimes show mitotic figures.

Lymphocytes are small lymphocytes, approximately $5 \mu \mathrm{m}$ in cell diameter, and have a round nucleus with dense peripheral masses of chromatin. The cytoplasm is relatively dark in appearance, forming a thin rim around the nucleus (Fig. 10). Such small lymphocytes are the second most frequent hemopoietic cells at 3 days of age. Myelocytes and megakaryocytes, if present, are almost negligible in number.

At 3 and 5 days of age, in addition to hemopoietic cells, macrophages are sometimes found in the marrow. They are usually irregular in shape and seen around or between vessels. Macrophages are characterized by the presence of a variety of inclusions (Fig. 11). The inclusions, $1-3 \mu \mathrm{m}$ in diameter, are generally spherical in shape, and they appear to be, for the most part, derived from phagocytosis of degraded blood cells, i.e., granulocytes and erythroid cells.

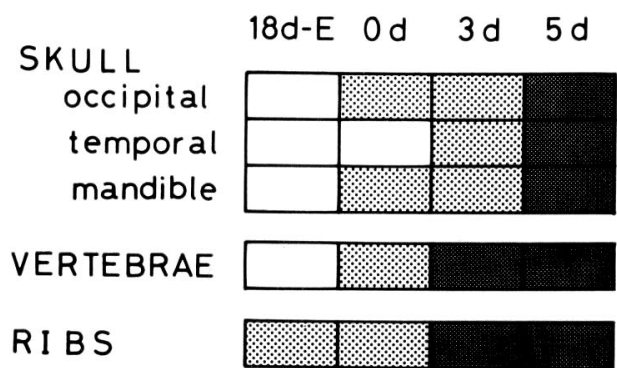

UPPER EXT. sca.\& hu. metacalpals
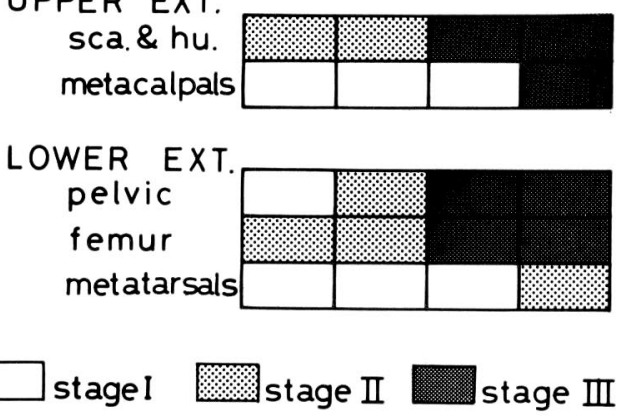

Fig. 7. Development of hemopoiesis in the marrow of various bones. $18 d-E$ 18th day of embryo, $O d$ at birth, $3 d$ 3rd day, $5 d$ th day after birth, sca. \& hu. scapula and humerus.

\section{DISCUSSION}

The total volume of the bone marrow in the whole body can be obtained with accuracy using serial sections of the body. Not only precise measurement of the marrow volume but also qualitative observations are possible on the hemopoietic tissue in various regions by means of serial sections. However, measurement of the marrow volume by means of serial sections may encounter some disadvantages. For example, it is not always easy to cut serially the body in toto. Even for the mouse, serial sections can hardly be made of mice older than 10 days. In this study, the observations are practically limited only to late embryonic and early postnatal mice.

As shown in the results, the bone marrow exhibits a marked increase in volume after birth. In the mouse, as is generally known, the liver is the central hemopoietic organ, especially for erythropoiesis during fetal life (Thomas and Yoffey, 1964; Rifkind et al., 1969; Jones, 1970; FuKudA, 1976; EnZAN et al., 1978). In the rat, hemopoietic activity in the liver is known to decline markedly during the last four days of intrauterine life, and erythropoiesis in the bone marrow becomes active successively (Lucarelli et al., 1968; Nagel et al., 1981). Thus a marked increase in the total volume of the bone marrow after birth represents the increased activity of the marrow hemopoiesis.

In adult mice, significant hemopoiesis is seen in the splenic red pulp as well as in 


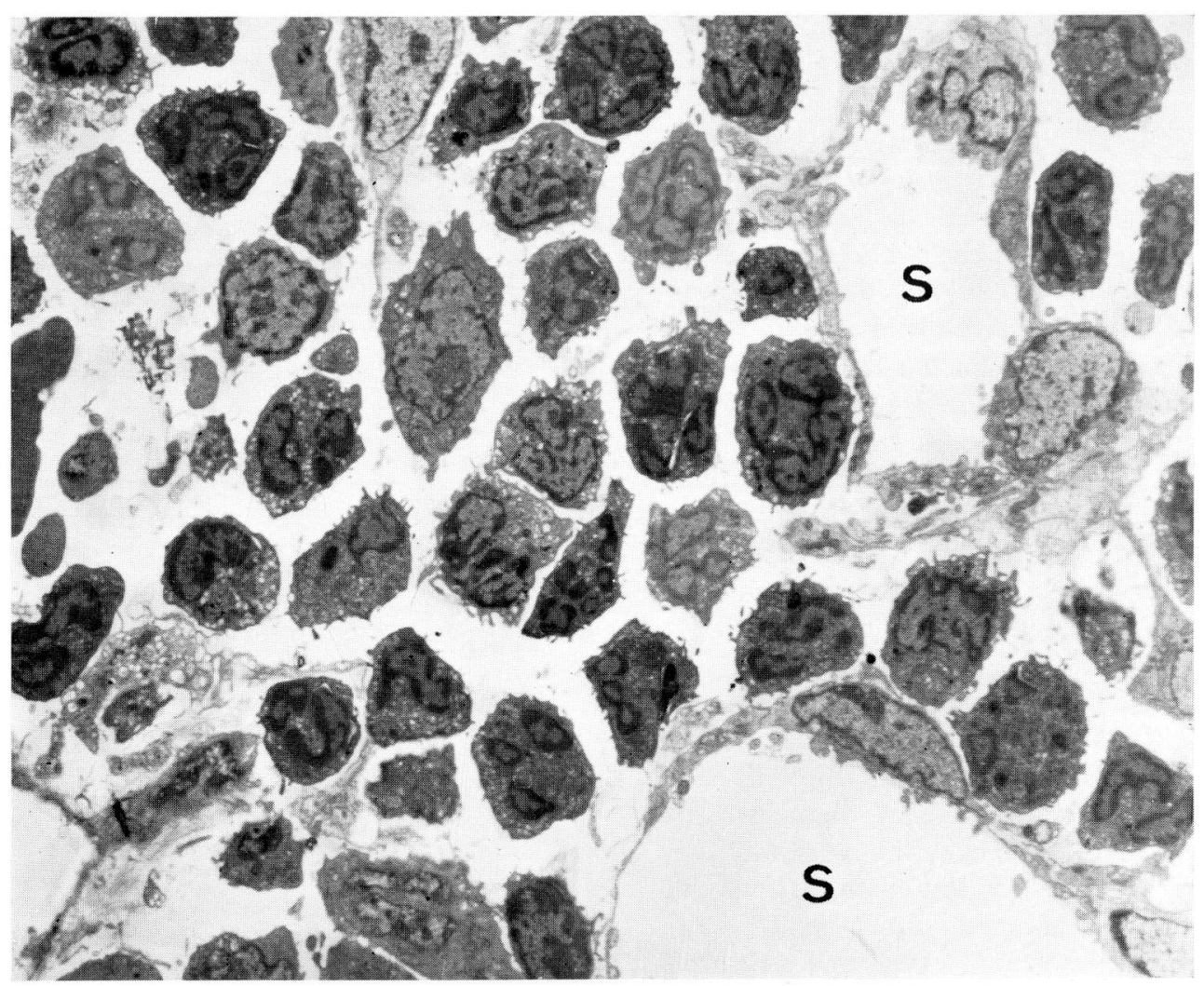

Fig. 8. An electron micrograph of mandibular bone marrow at 3 days of age. Mature neutrophils are accumulated around and between the sinusoids $(S) . \quad \times 2,700$

the bone marrow (review: Fruhman, 1970). In embryonal life, as seen in the results, the spleen is developed much more than the bone marrow. The splenic volume shows a steep rise in late embryonal life to be almost twice as large at birth as at 18 days of embryo. In the embryonic spleen, most of the splenic pulp is red, which appears to supplement decreasing activity in the hepatic hemopoiesis in late embryonic life. During five days after birth, the splenic red pulp undergoes almost six-fold increase in volume. As reported previously, the spleen in newborn mice is most active in hemopoiesis, particularly erythropoiesis, and the red pulp gradually increases in volume until 40 days of age (SASAKi et al., 1982, 1983; Matsumura et al., 1983). But blood production in the spleen seems to be too small in scale to supply the increasing need of blood cells after birth. Hemopoiesis then begins and becomes very active in the bone marrow. Thus, during the first five days in life, the marrow rapidly becomes greater in volume than the splenic red pulp.

As shown in the results, hemopoiesis in the bone marrow is established through the following three stages: 1) formation of the marrow space, 2) accumulation of neutrophils in the marrow cavity, 3) appearance of hemopoietic cells. At the second stage, neutrophils, which accumulate within the cavity, are typical mature forms. Immature granuloid cells, such as myeloblasts or myelocytes, are not recognized in the accumulation of neutrophils. Therefore, it is unlikely that the neutrophils are formed in the marrow, and they are considered to have migrated into the marrow cavity. As is well 


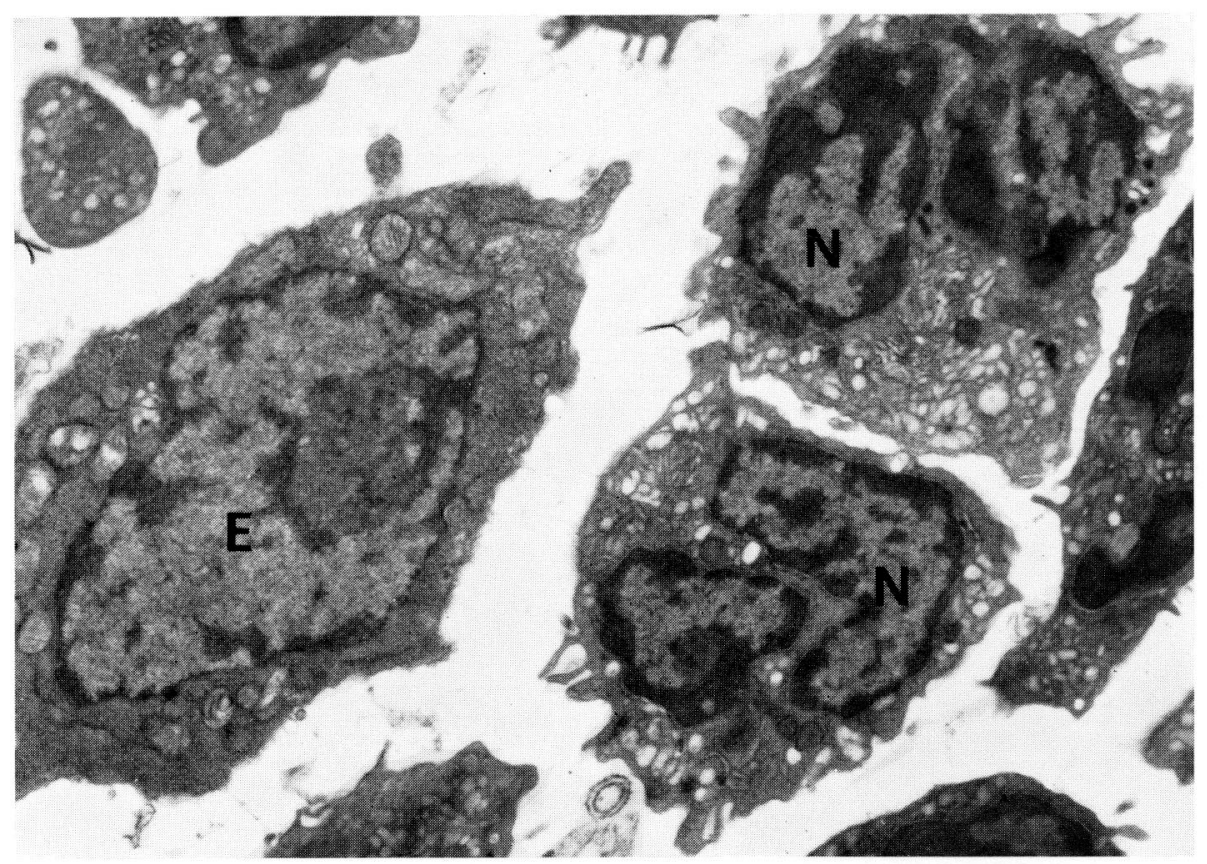

Fig. 9. Mandibular bone marrow at 3 days of age. Large erythroblast ( $E$ ) has a light and large nucleus with a well developed nucleolus. $N$ neutrophil. $\times 10,000$

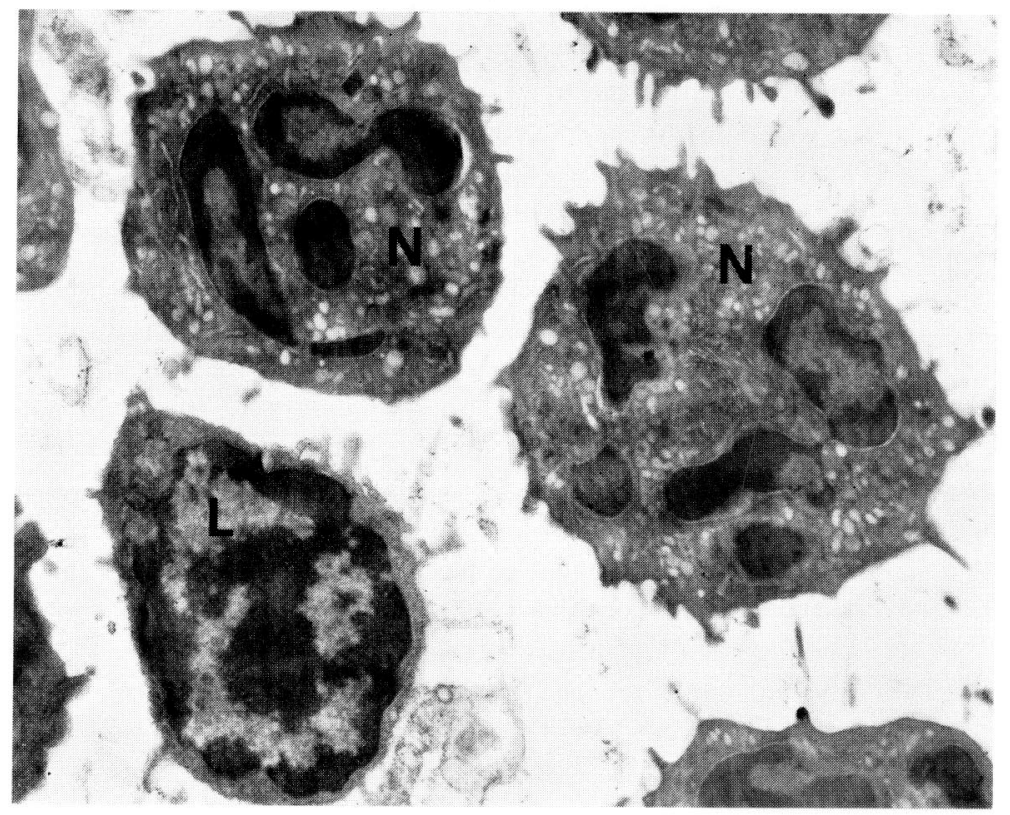

Fig. 10. Mandibular bone marrow at 3 days of age. Lymphocyte $(L)$ is small, and the cytoplasm appears a thin and dark rim around the nucleus. Neutrophils $(N)$ have a well lobulated nucleus and many small granules in their cytoplasm. $\times 10,000$ 


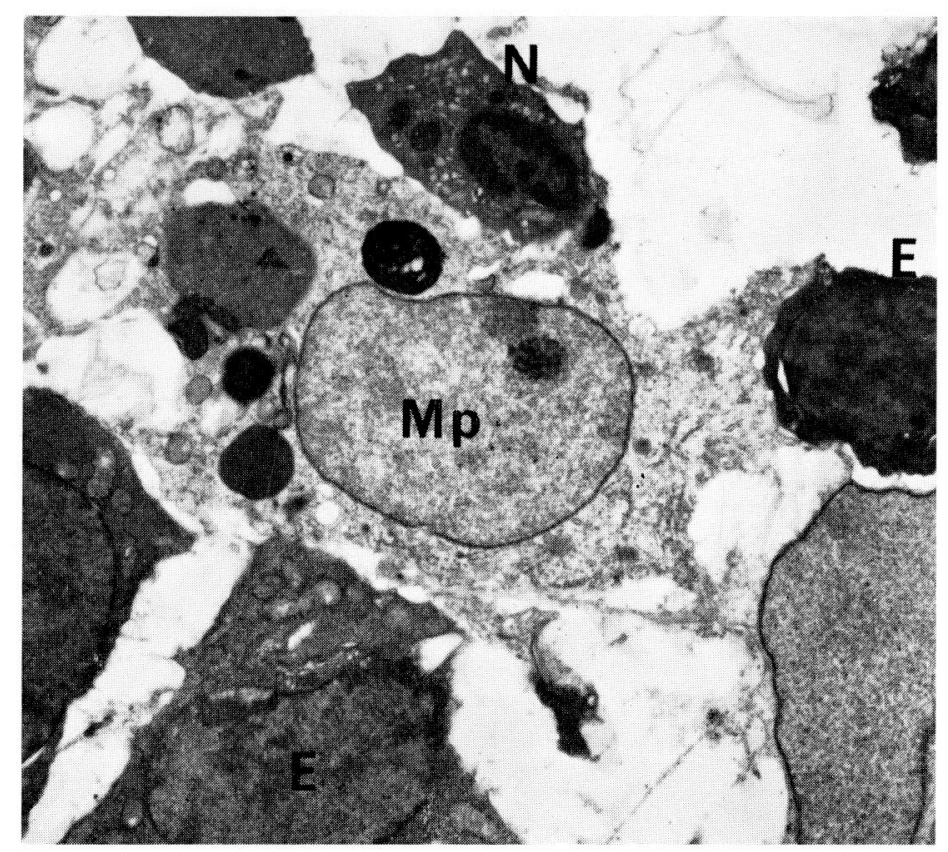

Fig. 11. A macrophage in mandibular bone marrow at 5 days of age. Macrophage $(M P)$ has a variety of inclusions. E erythroblast, $N$ neutrophil. $\times 5,000$

known, neutrophils play a primary role in inflammatory conditions (review; CLine, 1975). Prior to establishment of marrow hemopoiesis, the marrow cavity is formed within the degenerated cartilaginous tissue (CHEN and WeIss, 1975; ENZAN et al., 1983). The degenerated or degenerating cartilaginous tissue is thought to promote leukocyte emigration, as is the case in inflammation (Hurley, 1964; Ryen and Hurley, 1966). Thus collection of neutrophils seen at first in the marrow cavity is considered as emigration occurring as a result of a kind of inflammation, not pathological but physiological in nature. These neutrophils are probably derived from the fetal hemopoietic tissue, i.e., liver. At the third stage, hemopoiesis actually starts in the bone marrow. As shown in Figure 7, the marrow hemopoiesis starts at 0 to 3 days of age.

It has been reported that the earliest hemopoietic cells, appearing in the bone marrow of human fetuses and chickens, are similar to the stem cells described by vaN Bekkum and others (1971) (Chen and Weiss, 1975; Sorrell and Weiss, 1980). Such candidate stem cells are known to have a light nucleus with large nucleoli, and are to be distinct from small lymphocytes. But such cells as are morphologically similar to the stem cells are not definitely recognizable in the mouse bone marrow. The hemopoietic cells that are observed at the beginning of marrow hemopoiesis are erythroblasts, as mentioned in the results. In the neonate bone marrow, the majority of erythroblasts are large or extra-large erythroblasts according to our classification by electron microscopy (SASAKI and Ito, 1981; SaSAKi et al., 1981, 1982, 1983). Such large erythroblasts are quite few in frequency in the adult bone marrow. As reported previously, two types of small lymphocytes can be recognized by electron microscopy in the adult marrow; dark and light small lymphocytes (SASAKI and ITO, 1978, 1980a, 1980b). The small lymphocytes in the neonatal bone marrow are morphologically of the dark 
type, and few or almost no light small lymphocytes are observed early in life (SASAKI and ITO, 1978).

In the late embryonic and early postnatal mouse, the thymus is the largest and primary lymphatic organ. On the other hand, peripheral lymphatic tissues, such as the splenic white pulp, lymph nodes and Peyer's patches, begin to develop at 3 to 5 days after birth. As is generally accepted, the development of the peripheral lymphatic tissue is dependent on the central lymphatic organ. During the first five days in life, the thymus is thought to release lymphocytes to the peripheral lymphatic tissue on a large scale. As mentioned above, lymphocytes in the neonatal bone marrow are regarded as dark small lymphocytes, and they appear to be morphologically different from the thymus derived small lymphocytes in the peripheral lymphatic tissue (ABE and Iто, 1970; AвE et al., 1973). The origin and nature of small lymphocytes in the neonatal bone marrow may be studied particularly in relation to stem cells in hemopoiesis.

\section{REFERENCES}

Abe, K. and T. Ito: Fine structure of small lymphocytes in the thymus of the mouse: qualitative and quantitative analysis by electron microscopy. Z. Zellforsch. 110: 321-335 (1970).

Abe, K., K. Sasaki and T. Ito: Comparative ultrastructure and cytometric analysis of small lymphocytes in haemopoietic organs of neonatal mice. J. Anat. 115: 393-406 (1973).

Bekkum, D. W. van, M. J. van Noord, B. Maat and K. A. Dicke: Attempts at identification of hemopoietic stem cell in mouse. Blood 38: 547-558 (1971).

Bukulya, B. and A. Balázs : Data on the electron microscopy of the bone marrow in late embryonal and adult rats. Acta Med. Acad. Sci. Hung. 25: 383-394 (1968).

Chen, L. T. and L. Weiss: The development of vertebral bone marrow of human fetuses. Blood 46: 389-408 (1975).

Cline, M. J.: The white cell. Harvard University Press, Massachusetts, 1975.

Dietrich, H. F. and A. R. Fontaine: A decalcification method for ultrastructure of echinoderm tissues. Stain Technol. 50: 351-354 (1975).

Dietz, A. A.: Distribution of bone marrow, bone and bone-ash in rabbits. Proc. Soc. Exp. Biol. Med. 29: 34-37 (1931).

Earl, F. L., B. E. Melveger and R. L. Wilson: The hemogram and bone marrow profile of normal neonatal and weanling beagle dogs. Lab. Anim. Sci. 23: 690-695 (1973).

Enzan, H., H. Hara, T. Izumi and T. Ohkita: Morphologic and radiological observation on the earliest bone marrow formation in human embryos and fetuses. Acta pathol. jap. 33: 439-446 (1983).

Enzan, H., H. Takahashi, M. Kawasaki, S. Yamashita and T. Ohkita: Light and electron microscopic observations on hepatic hematopoiesis of human fetuses. Acta pathol. jap. 28: 411426 (1978).

Fairman, E. and G. W. Corner: The bone-marrow volume of the albino rat. Anat. Rec. 60: 1-4 (1934).

Fruhman, G. J.: Splenic erythropoiesis. (ed. by) A. S. Gordon: Regulation of hematopoiesis. Vol. 1. Red cell production. Appleton-Contury-Crofts, New York, 1970 (p. 339-368).

Fukuda, T.: Fetal hemopoiesis. II. Electron microscopic studies on human hepatic hemopoiesis. Virchow Arch. B. Cell Pathol. 16: 249-270 (1974).

Haas, R. J., D. Hoelzar, E. Kurrle, B. Landenberger and U. Winkler: Experimental analysis of developing hemopoiesis in fetal bone marrow. Pediat. Res. 10: 164-168 (1976).

Hudson, G: Bone marrow volume in guinea-pigs. J. Anat. 92: 150-161 (1958). 
Hurley, J. V.: Substances promoting leukocyte emigration. Ann. New York Acad. Sci. 116: 918-935 (1964).

Jones, R. O.: Ultrastructure analysis of hepatic haematopoiesis in the foetal mouse. J. Anat. 107: 301-314 (1970).

Kalpaktsoglou, P. K. and J. L. Emery: The effect of birth on the haemopoietic tissue of the human bone marrow. A histological study. Brit. J. Haematol. II: 453-460 (1965).

Kindred, J. E.: A quantitative study of the hemopoietic organs of young adult albino rats. Amer. J. Anat. 71: 207-243 (1942).

Lucarelli, G., A. Porcellini, C. Carnevali, A. Carmena and F. Stohlman, Jr: Fetal and neonatal erythropoiesis. Ann. New York Acad. Sci. 149: 544-559 (1968).

Matsumura, G., K. Sasaki and T. Ito: Histological studies of erythropoiesis in the splenic red pulp of the mouse: observations using semithin plastic sections (In Japanese). Hokkaido J. Med. Sci. 58: 112-118 (1983).

Mechanik, N.: Untersuchungen über das Gewicht des Knochenmarkes des Menschen. Z. Anat. Entw.-Gesch. 79: 58-99 (1926).

Nagel, M. D., J. Nagel and R. Jacquot : Early erythropoiesis in foetal rat bone marrow: evidence for a liver-to-bone marrow relay. J. Embryol. exp. Morphol. 64: 275-293 (1981).

Nye, R. N.: Bone marrow volume in rabbits. Proc. Soc. Exp. Biol. Med. 29: 34-37 (1931).

Rifkind, R. A., D. Chui and H. Epler: An ultrastructural study of early morphogenetic events during the establishment of fetal hepatic erythropoiesis. J. Cell Biol. 40: 343-365 (1969).

Ryen, G. B. and J. V. Hurley : The chemotaxis of polymorphonuclear leucocytes towards damaged tissue. Brit. J. exp. Pathol. 47: 530-536 (1966).

Sasaki, K. and T. Ito: Sex-related changes in the population of lymphocytes in the bone marrow of the mouse. An electron microscopic study. Arch. histol. jap. 41: 389-400 (1978).

: Effects of gonadectomy and testosterone on lymphocytes in the bone marrow of the mouse: an electron microscopic study. J. Anat. 130: 429-438 (1980a).

: Effects of pregnancy and lactation on lymphocytes in the bone marrow of the mouse: a quantitative electron microscopic study. Arch. histol. jap. 43: 211-219 (1980b).

-: Effects of estrogen and progesterone on the spleen of the mouse: a light and electron microscopic study. Arch. histol. jap. 44: 203-213 (1981).

Sasaki, K., G. Matsumura and T. Ito: Effects of pregnancy on erythropoiesis in the splenic red pulp of the mouse: a quantitative electron microscopic study. Arch. histol. jap. 44: 429-438 (1981).

- _- Morphometric analysis of postnatal erythropoiesis in the spleen and bone marrow of the mouse. Arch. histol. jap. 45: 247-255 (1982).

: A quantitative morphology of nucleoli of erythroblasts in the mouse spleen: an electron microscopic study. Arch. histol. jap. 46: 43-49 (1983).

Sorrell, J. M. and L. Weiss: Cell interactions between hematopoietic and stromal cells in the embryonic chick bone marrow. Anat. Rec. 197: 1-19 (1980).

Thomas, D. B. and J. M. Yoffey : Human foetal haematopoiesis. II. Hepatic haematopoiesis in the human foetus. Brit. J. Haematol. 10: 193-197 (1964).

Tilney, N. L.: Patterns of lymphatic drainage in the adult laboratory rat. J. Anat. 109: 369-383 (1971).

佐々木和信

䎡060 札幌市北区北15条西 7 丁目

北海道大学医学部

解剖学教室
Dr. Kazunobu SASAKI

Department of Anatomy

Hokkaido University School of Medicine

Sapporo, 060 Japan 